\title{
The Occurrence of Delayed Adverse Health Effects in Dental Personnel after Exposure to Mercury
}

\section{Hilt $B^{1,2 *}$, Sletvold $\mathrm{H}^{3}$ and Svendsen $\mathrm{K}^{4}$}

${ }^{1}$ Department of Occupational Medicine, St. Olav University Hospital in Trondheim, Norway

${ }^{2}$ Department of Public Health and General Practice, Faculty of Medicine, Norwegian University of Science and Technology, Trondheim, Norway

${ }^{3}$ Private Practice, Trondheim, Norway

${ }^{4}$ Department of Industrial Economics and Technology Management, Norwegian University of Science and Technology, Trondheim, Norway

\begin{abstract}
This paper gives some background information and sums up the results from research on possible late health effects in dental personnel after their occupational exposure to mercury from handling dental amalgam. We assessed that $0.5-2.8 \%$ of female dental assistants had possible delayed health injuries which mainly affected cognitive functions as a result of their occupational exposure to metallic mercury. Similar findings were not observed in dentists. When we followed all birth deliveries of 5,493 dental personnel compared to all other births in Norway from 1967 to 2006 in the National Birth Registry of Norway, we found no increase in the occurrence of malformations or other reproductive abnormalities in the dental personnel.
\end{abstract}

Keywords: Dental amalgam; Metallic mercury; Dental personnel; Cognitive; Reproduction

\section{Introduction}

In 2005 a Norwegian television documentary focused once more on the possible late adverse health effects on both cognitive function and reproduction in dental personnel subsequent to their exposure to metallic mercury from the handling of dental amalgam. This aroused a certain public awareness that resulted in a modest research grant from the Royal Ministry of Labour and Inclusion to find out if this was a real problem for this occupational group which has a majority of female employees. The documentary was partly built on unpublished data from a pilot study in Norway and from a large cohort study of dental assistants in New Zealand.

After having been granted most of the modest research funds, we, at the Department of Occupational Medicine at the St. Olav University Hospital in Trondheim, together with other researchers in the region and at the Norwegian University of Science and Technology, initiated some projects on neurobehavioral complaints and cognitive function in past and present dental personnel from the region of central Norway. A little later, we started a project looking at reproductive effects in past and present female dental personnel from the whole country. This presentation is a short summary of the findings from the different parts of the project with reference to some international publications from the project and elsewhere.

\section{Ethics}

The research was approved by the Ethical Committee for Medical Research in Central Norway and we had a licence for personal registration from the Norwegian Social Science Data Service. The conduct of the studies was deemed to be in accord with the Helsinki Declaration on Medical Research Ethics.

\section{Working Conditions in Dental Health Care and Health Related Issues}

In the initial survey we inquired, by a general questionnaire, about past and present working conditions together with some general health issues, and used the questionnaire Euroquest [1] to elucidate the occurrence of symptoms and health complaints related to neurological diseases, mood, memory, ability to concentrate, sleep, fatigue, and psychosomatic symptoms. The answers given by 1,193 dental personnel from central Norway were compared to answers given by a sex and agematched control group from the general population $[2,3]$.

There was no increase in the occurrence of diseases or complaints from the respiratory organs or the musculoskeletal system, nor any other diseases, such as migraine, in the participants.

Female dental assistants showed a slight increase in some symptoms and complaints with $2.5 \%$ having at least four Euroquest symptoms often or more frequently compared to $0.9 \%$ in the control group $(\mathrm{p}=0.04)$ [3]. We assessed that $0.5-2.8 \%$ of female dental assistants had possible delayed health injuries, mainly affecting cognitive functions, as a result of their occupational exposure to metallic mercury. For both male and female dentists there was no increase in cognitive health complaints when their answers were compared to answers from a group of control subjects with higher education [2].

From our questionnaire survey of working conditions and the literature, we achieved some insight into the use of metallic mercury in Norwegian dental health care during the last 50 years. The Norwegian National Institute of Occupational Health has, in the same period, done useful, but unsystematic, measurements of mercury in urine in dental personnel [4]. We have reason to assume that the exposure to mercury varied considerably according to working methods and conditions both between clinics and over time. The employment of a special form of Copper amalgam that was used in Norway up until the eighties, and that consisted of solid tablets that had to be heated in order to be used as amalgam, probably entailed the highest exposure to mercury vapour. However, also other methods of preparing the amalgam and spills of mercury in general will have contributed to exposures [5].

*Corresponding author: Prof. Bjørn Hilt, Department of Occupational Medicine, St. Olav University Hospital Trondheim, PO Box 3250 Sluppen, N-7006 Trondheim, Norway, Tel: +47 72571407, +47 90069490; Fax: +47 72571347; E-mail: bjorn.hilt@stolav.no

Received January 24, 2014; Accepted March 11, 2014; Published March 13, 2014

Citation: Hilt B, Sletvold H, Svendsen K (2014) The Occurrence of Delayed Adverse Health Effects in Dental Personnel after Exposure to Mercury. Dentistry 4 220. doi:10.4172/2161-1122.1000220

Copyright: (C) 2014 Hilt B, et al. This is an open-access article distributed under the terms of the Creative Commons Attribution License, which permits unrestricted use, distribution, and reproduction in any medium, provided the original author and source are credited. 
We also experienced that a detailed questionnaire on exposures and working conditions could be difficult for many of the participants to fill in correctly. Consequently, we lacked complete exposure information for many of the participants in our analyses. We were, however, pleased that the resulting observed misclassifications were mainly non-differential, and that the frequency of false positive exposure information (specificity) was higher than the frequency of false negative information (sensitivity) [6].

Based on the initial survey we performed a neuropsychological investigation of 91 of the female participants. In these presumably healthy persons we found no relation between their cognitive function and our assessment of their occupational exposure to mercury. We did, however, in 28 subjects for whom measurements were available, find a weak relation between the results on a test for visual memory and the previously measured levels of mercury in urine obtained from the National Institute of Occupational Health [7].

Based on a few findings from the initial survey that were hard to interpret, the Ministry granted some additional funding for making a closer investigation of some reproductive issues in 2008. Together with the Department of Occupational Medicine at Haukeland University Hospital and the National Birth Registry of Norway we followed all the deliveries of 5,493 dental personnel compared to all other births in Norway from 1967 to 2006. We found no increase in the occurrence of malformations or other reproductive abnormalities in the dental personnel [8].

\section{Discussion}

Previous investigations of symptoms and cognitive dysfunction in dental personnel have shown diverging results [9]. The pilot study from Bergen that partly initiated our studies was published in the meantime and shows significant differences in the occurrence of symptoms (Euroquest) between dental assistants and enrolled nurses [10]. In a later publication from the cohort from New Zealand with 30 years of follow up, it was also shown that dental assistants had more symptoms, and that a greater share of them had been subject to hysterectomy [11]. A comprehensive Danish register investigation on hospital diagnoses showed no increase in the risk of neurological diseases of kidney diseases in dental assistants [12].

In spite of the research carried out during the last years, there is still controversy in Norway as to whether dental personnel can have delayed (late) adverse health effects from previous exposure to metallic mercury from dental amalgam. In a recent ruling from the Supreme Court of Norway, certain cognitive health complaints were accepted as an occupational disease in a former dental assistant. From our research, and on empiric ground, one cannot give a general answer as to whether dental assistants have been injured or not. The question of possible adverse health effects has to be dealt with on an individual basis based on a thorough medical history from each subject and on other investigations.

\section{Conclusions}

- Exposure to metallic mercury in dental health care has varied considerably between clinics and over the years.

- Cognitive late effects from previous exposure to metallic mercury in dental health care are possible, but are rare, and have to be assessed on an individual basis.

- On a group basis there was no relation between assessed exposure to mercury and results of the comprehensive neuropsychological tests, whereas there was a weak association between visual memory and previously measured urine mercury levels.

- There were no excess adverse reproductive effects detectable when the birth deliveries of 5,493 dental personnel were followed from 1967 to 2006 at the National Birth Registry of Norway.

\section{Acknowledgements}

The research was supported by grants from the Royal Norwegian Ministry of Labour and Social Inclusion. We thank the authors who contributed to the original papers based on the research and the dental personnel who participated and Patricia Flor for useful linguistic help with this manuscript.

\section{References}

1. Carter N, Iregren A, Soderman E, Olson BA, Karlson B, et al. (2002) EUROQUEST--a questionnaire for solvent related symptoms: factor structure, item analysis and predictive validity. Neurotoxicology 23: 711-717.

2. Hilt B, Svendsen K, Syversen T, Aas O, Qvenild T (2011) Occurrence of cognitive and neurological symptoms in norwegian dentists. Saf Health Work 2: 176-182.

3. Hilt B, Svendsen K, Syversen T, Aas O, Qvenild T, et al. (2009) Occurrence of cognitive symptoms in dental assistants with previous occupational exposure to metallic mercury. Neurotoxicology 30: 1202-1206.

4. Lenvik K, Woldbæk T, Halgard K (2006) Exposure to mercury in dental personnel. Nor Tannlaegeforen Tid 115: 350-355.

5. Svendsen K, Syversen T, Melo I, Hilt B (2010) Historical exposure to mercury among Norwegian dental personnel. Scand J Work Environ Health 36: 231 241.

6. Svendsen K, Hilt B (2011) The agreement between workers and within workers in regard to occupational exposure to mercury in dental practice assessed from a questionnaire and an interview. J Occup Med Toxicol 6: 8.

7. Sletvold H, Svendsen K, Aas O, Syversen T, Hilt B (2012) Neuropsychological function and past exposure to metallic mercury in female dental workers. Scand J Psychol 53: 136-143.

8. Heggland I, Irgens A, Tollanes M, Romundstad P, Syversen T, et al. (2011) Pregnancy outcomes among female dental personnel--a registry-based retrospective cohort study. Scand J Work Environ Health 37: 539-546.

9. Clarkson TW, Magos L (2006) The toxicology of mercury and its chemical compounds. Crit Rev Toxicol 36: 609-662.

10. Moen B, Hollund B, Riise T (2008) Neurological symptoms among dental assistants: a cross-sectional study. J Occup Med Toxicol 3: 10.

11. Jones L, Bunnell J, Stillman J (2007) A 30-year follow-up of residual effects on New Zealand School Dental Nurses, from occupational mercury exposure. Hum Exp Toxicol 26: 367-374.

12. Thygesen LC, Flachs EM, Hanehoj K, Kjuus H, Juel K (2011) Hospital admissions for neurological and renal diseases among dentists and dental assistants occupationally exposed to mercury. Occup Environ Med 68: 895901. 